\title{
Effect of Potential Energy Stored in Reactor Facility Coolant on NPP Safety and Economic Parameters
}

\author{
G. I. Toshinsky ${ }^{1}$, O. G. Komlev ${ }^{1}$, I. V. Tormyshev ${ }^{1}$, V. V. Petrochenko ${ }^{2}$ \\ ${ }^{1}$ FSUE State Scientific Center Institute for Physics and Power Engineering (SSC IPPE), Obninsk, Russia \\ ${ }^{2}$ JSC “AKME Engineering”, Moscow, Russia \\ Email: toshinsky@ippe.ru
}

Received June 23, 2011; revised January 19, 2013; accepted February 8, 2013

Copyright (C) 2013 G. I. Toshinsky et al. This is an open access article distributed under the Creative Commons Attribution License, which permits unrestricted use, distribution, and reproduction in any medium, provided the original work is properly cited.

\begin{abstract}
Potential (non-nuclear) energy stored in reactor facility coolant is a crucial factor determining the NPP safety/hazard characteristics as it is inherent property of the material and cannot be changed. Enhancing safety of the NPP with traditional type reactor facilities, in which potential energy is stored in large quantities, requires buildup of the number of safety systems and in-depth defense barriers, which reduce the probability of severe accidents (but do not exclude the opportunity of their realization) and seriousness of their consequences. Keeping the risk of radioactivity release for different type reactor facilities at a same level of social acceptability, the number of safety systems and in-depth defense barriers, which determine essentially the NPP economical parameters, can be reduced with diminishing the potential energy stored in the reactor facility. To analyze the effect of potential energy on reactor facility safety/hazard, a diagram of reactor facility hazard has been proposed. It presents a probability of radioactivity release as a function of radioactivity release values for reactor facilities with identical radiation potential, which differ by values of potential energy stored in coolant. It is proposed to account NPP safety/hazard effect on economics by adding a certain interest on the electricity cost for making payments in a special insurance fund assigned to compensate the expenses for elimination of consequences of a possible accident.
\end{abstract}

Keywords: Potential Energy; NPP Safety; Coolant

\section{Introduction}

Reactor facility (RF) coolant very much defines its engineering design, safety and economic characteristics of the nuclear power plant's (NPP) power-unit. There is no ideal coolant that exists in nature. Each coolant used or proposed to be used possesses the own specific features, whose seriousness is determined by the reactor purpose and external conditions. During a long process of mastering the different coolants their drawbacks were compensated (in case it was possible and expedient) by technical means and organizing measures that in different ways affected their technical and economical parameters.

Some of the inspected coolants did not pass practice tests (mercury, $\mathrm{N}_{2} \mathrm{O}_{4}$, organic coolant, $\mathrm{CO}_{2}$ ). Finally, option for coolant is determined by requirements to the $\mathrm{RF}$, and is depending on a degree of mastering the coolant with reference to the conditions of usage.

The crucial coolant characteristic is a value of potential energy stored in a volume unit of coolant. This parameter defines a safety level of the RF and NPP power- unit.

In the system approach safety and hazard are considered as interconnected concepts. Therefore, in order to understand better how to achieve a high safety level, the nature of hazard peculiar to a nuclear power facility (NPF) should be analyzed.

The hazard from the NPF is determined by two factors:

- Radiation potential accumulated, i.e., total radioactivity (more exactly, radiotoxicity) contained in the reactor facility. This factor determines the level of heat decay too;

- Probability of radioactivity release into the environment for different initial events.

The first factor does not depend strongly on the RF type, because total radioactivity contained in the RF and determined mainly by the amount of fission products is associated primarily with thermal power of the reactor and duration of its operation at this power level, i.e., by energy production.

The second factor depends on the RF type much stronger 
and is determined by reactivity margin, feedbacks, design features, and potential energy accumulated in the RF (nuclear energy, internal thermal energy, coolant compression energy, chemical energy), which in an event of its release can cause exhaust of radiotoxicity into the environment. Therefore, the hazard associated with the RF (for identical power levels and operation time) will be determined by the second factor.

The nuclear fission energy which can be released under conditions of reactivity accidents must be minimized in principle, as early as at the reactor design phase by limiting the reactivity margin, use of feedbacks, and by various engineering solutions to exclude a possibility of insertion of positive reactivity exceeding the delayed neutrons fraction.

Otherwise, potential (non-nuclear) energy stored in the RF primary circuit coolant is an inherent coolant property and cannot be changed by engineering solutions.

In the presented report the major advantages and drawbacks of different type coolants are compared, effect of potential (non-nuclear) energy stored in the RF coolant on NPP safety is considered. Along with this, the consideration is given to the certain related economic aspects of safety and issues of insurance against risks.

\section{Comparison of Different Coolants}

The major specific features peculiar to different coolants and conditioned by their natural properties are considered below.

\subsection{Water Coolant}

Owing to the fact that water has been mastered in traditional power, in the nuclear power (NP) water coolant is dominating. Heat can be well removed by water, water is available and cheap. Drawbacks of water coolant are as follows: high pressure in the primary circuit is required; being exposed to radiation and chemical interaction in emergency conditions with zirconium, water is disintegrating with release of hydrogen; water cannot be used in fast reactors (FR) because of hydrogen that is a good moderator of neutrons.

\subsection{Sodium Coolant}

Thermal and physical properties of sodium are very high and, therefore, as for sodium coolant, there is no alternative for fast breeder-reactors because of short doubling time of plutonium. The advantage of sodium and other liquid metals is that there is no necessity to maintain high pressure in the primary circuit. There are no limits on raw material resources. Drawbacks of sodium coolant are as follows: high chemical activity while reacting with air and water that is possible in accidental events, high in- duced gamma-activity hampering the access to the maintenance and repair equipment for a long time (2 - 3 weeks).

\subsection{Lead-Bismuth Coolant (LBC)}

Advantages of LBC are as follows: chemical inertness to water and air, lack of the necessity to maintain high pressure in the primary circuit, high nuclear-physical characteristics. LBC was mastered in conditions of operating the nuclear submarines' (NS) reactors [1]. However, for civilian NPPs this experience needs to be verified by operating the experimental-industrial reactor. The specific feature of LBC is that alpha-active polonium- 210 is accumulated in the process of operation. Along with this, operating experience has revealed that the personnel and environment safety is assured not only in normal operating conditions but in events of accidental leaks of LBC as well. Bismuth resources are limited but sufficient enough for real scale development of LBC cooled reactors.

\subsection{Lead Coolant}

Lead coolant possesses the same advantages as LBC and a lower level (by 4 orders of magnitude) of induced polonium activity. It is cheaper than LBC and its raw material resources are more available. The specific feature of lead coolant is higher melting temperature $\left(327^{\circ} \mathrm{C}\right)$, that is by $200^{\circ} \mathrm{C}$ higher than that of $\operatorname{LBC}\left(123.5^{\circ} \mathrm{C}\right)$. That drawback of lead will hamper operation of the RF. It will require use of robotic technologies for maintenance and repair with their development at non-reactor facilities and in conditions of full-scale tests.

\subsection{Helium Coolant}

The advantage of helium is that it is a noble inert gas compatible with all structural materials in a large range of temperatures. The specific features of helium are as follows: to remove effectively heat it requires high pressure in the primary circuit, to provide safety in an event of a LOCA type accident it requires low power density in the core, it requires special fuel and technology of its reprocessing.

\subsection{Coolants’ Technology}

All coolants need quality control in order to eliminate accumulation of solid deposits and assure corrosion resistance of selected structural materials for a given resource for the required temperature range. These tasks have been solved or can be solved.

For water it is necessary to maintain approximately 10 quality parameters within the required interval. For sodium it is necessary to maintain oxygen concentration to 
be lower than the given level. For LBC it is necessary to maintain concentration of dissolved oxygen in the given range to be within two orders of magnitude. Lead coolant needs fine control of dissolved oxygen concentration within a very narrow range. For helium fine purification from fly grit is required.

In Section 4 the basic coolants are compared by a value of stored potential energy.

\section{Limitations of Probabilistic Approach to Substantiation of Safety}

Upgrades of safety of the NPP with traditional type RFs require build up of the number of safety systems and defense-in-depth barriers, which diminish the probability of severe accidents and weight of their consequences.

While assessing this probability, failures of the equipment, safety systems, protection barriers, and personnel's errors are considered as random events.

However, because of the variety and high complication of the developing processes and lack of some initial data necessary for calculation, there are many uncertainties in the results of safety substantiation by the probabilistic safety analysis (PSA) methods as applicable to severe accidents, their probability being very low $\left(\sim 10^{-6}\right.$ per reactor-year and less). Therefore, these results do not possess the cogency value as required. Moreover, the PSA methods make no sense if we consider the preplanned initial events, for example, hijacking of the NPP by terrorists, when the safety systems, which are in a standby mode, and protection barriers can be disabled on purpose, and after a certain series of actions the exhaust of radioactivity can achieve a disastrous level.

While keeping the risk of radioactivity release from different type RFs at a similar, socially acceptable level, the number of safety systems and defense-in-depth barriers, which strongly determine the NPP technical and economical characteristics, can be reduced with a decrease of the potential energy accumulated in the RF, mainly in coolant. At this point, it is important that the high safety level at low value of potential energy stored in coolant can be achieved, mainly, due to elimination of the causes of severe accidents, i.e., deterministically.

\section{Potential Energy in Different Type Coolants}

The issues of accounting for potential (non-nuclear) energy, which can be released in external events (those considered to be beyond the design basis), were studied earlier [2,3] in the analysis of nuclear installations' safety. The importance of the analysis of such scenarios is verified by the fact that they also have been addressed by the IAEA [4].

The values of the specific (per a volume unit) stored potential energy for different coolants $E_{\text {pot}}$, which could be released in events of severe accidents, are summarized in Table 1 (the reference data were used in computations).

When analyzing the consequences of potential energy release, we should keep in mind the following:

- For water coolant some amount of stored thermal energy (potential compression energy) can be converted into kinetic energy of steam expansion (assessment in Table $\mathbf{1}$ is performed for adiabatic process) that cause mechanical destruction of the equipment and loss of core cooling. Moreover, in an event of the severe accident while steam chemically interacts with zirconium, thermal energy and hydrogen are released in large quantities; hydrogen, in turn, is a high-rating source of hazard;

- For sodium coolant while contacting with air, the release of stored chemical potential energy can cause fire and, in an event of an unfavourable scenario, also loss of core cooling; while contacting with water, thermal energy and hydrogen will be released in large quantities;

- For heavy liquid metal coolants (lead-bismuth alloy, lead) the stored thermal potential energy cannot be converted into kinetic energy, there is no significant release of energy in an event of coolant contacting with air, water, structural materials, there is no loss of core cooling in an event of tightness failure in the gas system, i.e. the LOCA type accident cannot occur.

\section{Safety Diagram}

As an illustration of the above postulates, Figure 1 presents a diagram showing the quality dependence of the probability of radioactivity release and its values for reactor facilities with identical radiation potentials, which

Table 1. The values of specific (per a volume unit) stored potential energy for different coolants.

\begin{tabular}{cccc}
\hline Coolant & Water & Sodium & $\begin{array}{c}\text { Lead, } \\
\text { lead-bismuth }\end{array}$ \\
\hline Parameter & $\begin{array}{c}\mathrm{P}=16 \mathrm{MPa}, \\
\mathrm{T}=300^{\circ} \mathrm{C}\end{array}$ & $\mathrm{T}=500^{\circ} \mathrm{C}$ & $\mathrm{T}=500^{\circ} \mathrm{C}$ \\
$\begin{array}{c}\text { Maximum potential } \\
\text { energy, }\end{array}$ & $\sim 21.9$ & $\sim 10$ & $\sim 1.09$ \\
$\begin{array}{c}\mathrm{GJ} / \mathrm{m}^{3} \text {, including: } \\
\text { Thermal energy }\end{array}$ & $\sim 0.90$ & $\sim 0.6$ & $\sim 1.09$ \\
$\begin{array}{c}\text { Including potential } \\
\text { compression energy }\end{array}$ & $\sim 0.15$ & None & None \\
$\begin{array}{c}\text { Potential chemical } \\
\text { energy of interaction }\end{array}$ & $\sim 11.4$ & With zirconium air $\sim 9.3$ & None \\
$\begin{array}{c}\text { Potential chemical } \\
\text { energy of interaction } \\
\text { of hydrogen released } \\
\text { with air }\end{array}$ & $\sim 9.6$ & $\sim 4.3$ & None \\
\hline
\end{tabular}




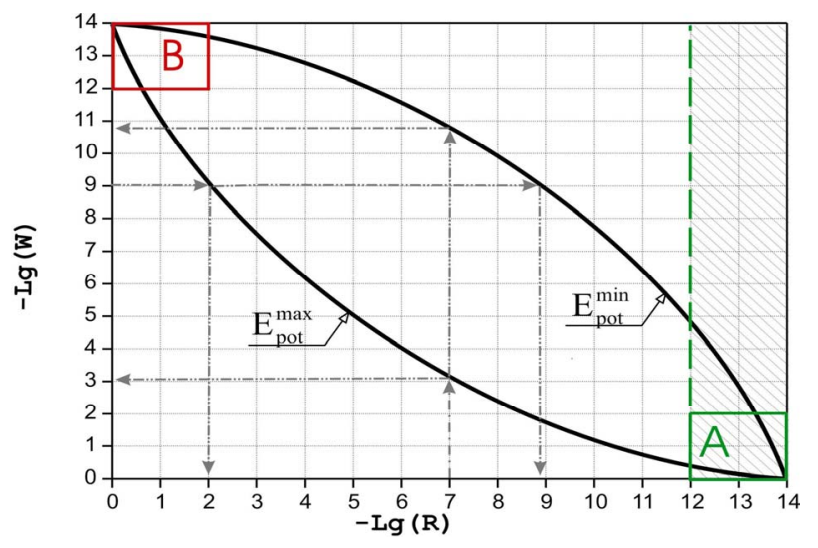

Figure 1. Safety diagram.

differ by values of internal potential energy stored in coolant.

On a vertical axis of the diagram a negative logarithm of probability of radioactivity release $\mathrm{W}$ is shown. On the horizontal axis a negative logarithm of radioactivity release in relative units $\mathrm{R}$ is shown (in case $\mathrm{R}=1$, the whole amount of radioactivity contained in the RF is released into the environment). The value of the stored potential energy is designated as $\mathrm{E}_{\text {pot }}$ for the corresponding curves.

In the part of the diagram designated as A, reactors of each type appear to be admissibly safe, because the estimation value of radioactivity release is below the permissible level (normal operating conditions). The dashed area defines admissible radioactivity release. The probability of such operating conditions is near 1 .

In the part of the diagram designated as $\mathrm{B}$, reactors of each type appear to be very hazardous, because nearly the whole amount of radioactivity stored in the RF would be released into the environment as a result of external impacts, which are beyond the design basis, their probability being very low.

Nevertheless, within these extreme situations there is a wide region of real accidents of different severity levels, on the safety diagram it is limited by corresponding curves on top and bottom. Within this range of the diagram, a safety level of different type RFs will considerably differ. For the identical probability of radioactivity release, its value will differ by several orders of magnitude as dependent on the stored potential energy, or at the same value of radioactivity release the probability of its realization will differ by several orders of magnitude.

Of course, the diagram proposed for the safety analysis of RFs with different coolants does not take into account several other factors, which also determine the value of radioactivity release. These factors, in particular, include capability of fuel to retain fission products at accidental temperatures, not to dissociate (if the fuel is a chemical compound), not to enter into exothermal chemical reac- tions like the fuel designed for high-temperature gas reactors, chemical compatibility of fuel with the coolant, the capability of coolant to retain the radioactivity under conditions of severe accidents development.

The value of radioactivity release also depends very strongly on the scenario of accident evolution determined by the design of the RF and power unit, behavior and scale of the initial events. Therefore, the diagram reflects the real situation correctly in terms of quality only for the potential energy stored in coolant, all other conditions being equal.

It is known [5] that for the NPP with traditional reactors (with a high value of potential energy stored in the RF coolant), safety and economic requirements are in contradiction. The highlighted conflict appears as follows: while heightening the safety requirements that could be expected for considerable growth of the number of power-units, the NPP economical parameters are deteriorating that is caused by necessary increase of the number and efficiency of used safety systems and defense-in-depth barriers.

A quality-based illustration of this situation is presented in Figure 2, where a cost (C) of the identical power NPPs is shown as a function of a regulated value of probability of severe accidents $\left(\mathrm{P}_{r}\right)$ for different values of potential energy $\mathrm{E}_{\text {pot }}$ stored in the RF coolant.

At the same time, all other conditions being equal (the same number of safety systems, defense-in-depth barriers), the probability of the severe accident $(\mathrm{P})$ will be the higher, the more there will be a value of potential energy stored in the RF coolant, which is qualitatively shown in Figure 3. All these highlight the importance of accounting for this parameter while developing the NPP design.

\section{Economic Aspects of Safety Insurance against Risk}

Historically, the NPP technical-economical parameters and safety characteristics are determined independently of each other. While designing the NPP, safety characteris-

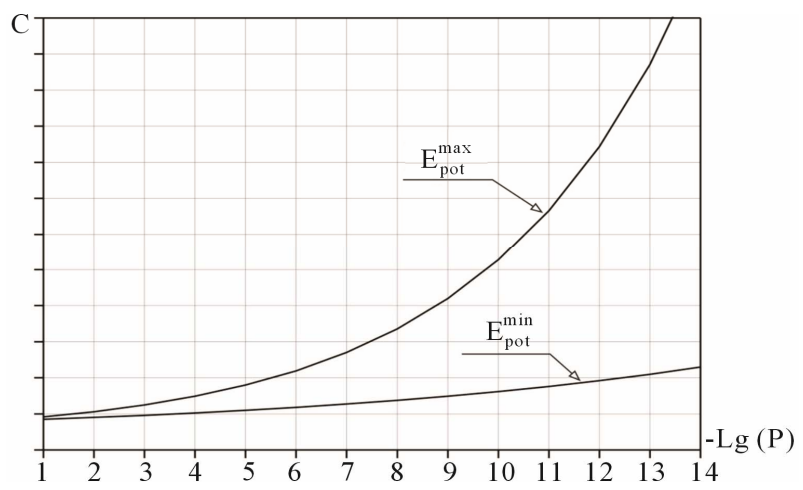

Figure 2. The NPP cost as a function of regulated probability of the severe accident. 


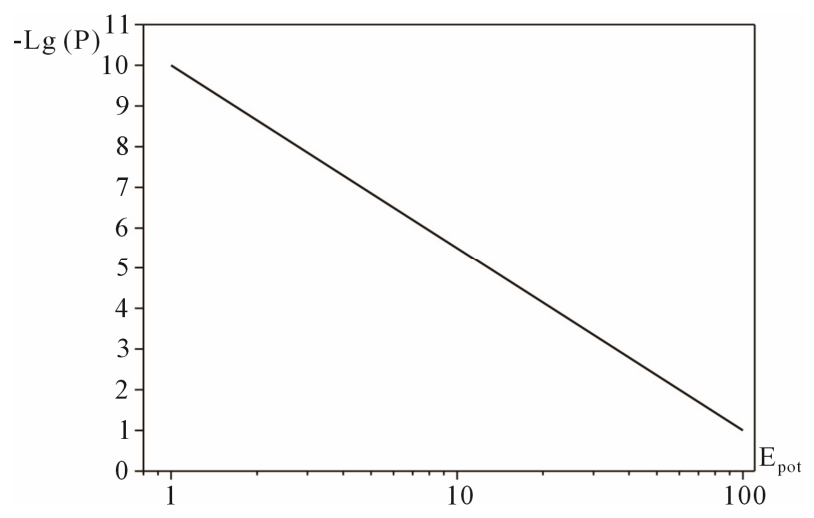

Figure 3. Probability of the severe accident as a function of potential energy stored in $R F$ coolant $\left(E_{\text {pot }}, M J / \mathbf{m}^{3}\right)$.

tics are introduced as limiting values in accordance with the regulatory (normative) documentation, in which the probability of severe accident is regulated, and cost parameters are minimized in compliance with the results of technical-economical calculations. Based on these results, the NPP project is chosen.

Such approach is not a stimulating factor in designing the RF with higher safety characteristics as compared with those required in the regulatory (normative) documentation. For example, if in the proposed NPP project the safety characteristics on probability of the severe accident are higher by one or two orders of magnitude, but the technical-economical ones are a few lower than those of the alternative NPP project, which safety characteristics meet the limiting values of the normative requirements, the former project will be rejected as being not enough competitive economically.

At the same time, the higher requirements must be made for the future large-scale nuclear power (NP), because the probability of the severe accident regulated in the normative documentation provides a socially acceptable value of frequency of its realization only at a current level of the total operating time of the NPP reactors that is less than 10,000 reactor-years.

In case in future the number of power-units is 10 times as much, to keep the expectation of frequency of severe accident realization at the current level, it will require to make this probability correspondingly 10 times as less in terms of a reactor-year [3].

It could be accounted by following the existing practice of developing the normative requirements for the future, which would orient the developers of new generation NPPs towards the higher safety parameters. However, at this, despite being at a higher level of safety, the NPP projects with the higher safety characteristics as compared with the normative ones could be rejected if their technical-economical characteristics are somewhat worse.

However, if we observe the provisions of "Safety Cul- ture" [6], where it is written that "As the priority of the NPPs is the highest, their importance determines the attention paid to the issues of safety", we can avoid this conflicting situation. For example, while calculating the cost of generated power, we can account the safety parameters of the designed NPPs in a way that the NPP with higher safety characteristics would not lose its competitiveness [7].

The latter could be ensured by charging a certain interest on the cost in order to make payments in a special insurance fund provided to compensate the expenditures for elimination of consequences of a possible accident $[8,9]$.

The lower the NPP safety indices are, the higher the interest charges must be, all other conditions being equal. That parameter could be a value of logarithm of normalized (per $1 \mathrm{GW}$ of set power) radioactive exhaust under the certain combination of unlikely initial events, which are identical for any type reactors. Such combination of events must be determined in the normative documentation on safety.

Experience of such charges to the cost of the NPP "production" is in Sweden where the expenditures of companies-energy suppliers provided for safe management of radioactive waste are compensated from the funds formed as taxes on electricity sales [10].

For the comparability of potential detriment, all indices of expenses for the compensation thereof must be correlated with a unit of set power of the NPP (normalized potential detriment (NPD)). The NPD also can be considered as a criterion to assign the rate for allocations to the insurance fund.

Therefore, in the system approach to substantiation of safety, the size of insurance payments, as well as expenses for the physical protection and guard force of the NPP must essentially depend on the value of the stored potential energy, which determines to a considerable extent the inherent self-protection of the RF.

When such approach is used for substantiation of safety, the capital expenditures and operating costs for the NPPs, in which the RFs with small margin of potential energy are used, also will become lower, and changeover to enhanced-safety NPFs will be economically stimulated.

Currently, when the normative approach to substantiation of safety is used, the innovative NPFs, in which severe accidents have been eliminated deterministically (so-called "risk-protected" reactors [11]), have no advantages over the evolutionary NPFs, for the latter ones the probability of the severe accident validated by probabilistic analysis methods, does not exceed $10^{-7}$ per reactor-year.

When comparing different RFs, we should take into account that the electricity product is peculiar two fea- 
tures, which distinguish it from other kinds of goods. These features are as follows: 1) electricity must be consumed when it is generated and electricity cannot be accumulated for future use by purchasing it when its rate is reduced and demands for electricity are low; 2) the standard quality of electricity produced by different power plants is the same, therefore, it is the cost of electricity that is only viable for the consumer and producer's profit (as the profit is proportional to a difference between the cost (tariff) and net cost).

Due to all mentioned above there will be vital even low reduction of the electricity net cost that can be provided by use of innovative RFs with a low value of potential energy stored in the coolant. For example, reduction of the electricity net cost by $5 \%$ under $10 \%$ of profitability of its production will result in profit increase by $50 \%$. Correspondingly, it will lead to reduction of the term of capital repayment or to reduction of the tariff and increase of sales volume at a liberalized electricity market.

\section{Conclusions}

- The most expedient way to upgrade the NPP safety that simultaneously improves the economic characteristics is use of RFs, in which the value of stored potential energy is the lowest and in which the inherent self-protection and passive safety properties can be realized to the maximal extent.

- This type RFs cannot amplify the external impacts; therefore, the scale of damages will be only determined by energy of the external impact, the exhaust of radioactivity being localized. Such type RFs will possess the robustness properties, which will ensure their enhanced stability not only in events of single failures of the equipment and personnel's errors, but also in events of malevolent actions, that is especially important for NP development in developing countries.

- Bearing in mind the importance of future changeover to nuclear power technologies, in which the inherent self-protection and passive safety properties are realized to the complete extent, the insurance payments and degree of physical protection and safeguard should be determined depending on a value of logarithm of radioactivity release in case of realization of external events, which probability is very low (but is possible in principle). Such events must be defined in the regulatory documentation that is the same for each type RFs.

- The above listed properties are to the highest extent peculiar to RFs cooled by heavy liquid-metal coolants (first of all, the already mastered LBC), which the certain countries have been developing in recent years. Among that type RFs Project SVBR-100 (leadbismuth fast reactor of $100 \mathrm{MWe}$ ) is the most available for realization. Construction of this reactor is pro- vided in Russian Federal Target Program "New Generation Nuclear Power Technologies for the 20102015 years and up to the year 2020". The Project is being realized within the frameworks of state-private partnership of joint venture OJSC "AKME-Engineering" established on a parity basis by State Atomic Energy Corporation "Rosatom" and Limited Liability Company "EuroSibEnergo".

\section{Acknowledgements}

The authors would like to thank SSC RF-IPPE employees S. V. Budarina and K. G. Mel'nikov for their assistance in preparation of the present Article.

\section{REFERENCES}

[1] C. A. V. Zrodnikov, G. I. Toshinsky, V. S. Stepanov, et al., "Lead-Bismuth Reactor Technology Conversion: From NS Reactors to Power Reactors and Ways of Increasing the Investment Attractiveness of Nuclear Power Based on Fast Reactors," International Conference IAEA "Fifty Years of Nuclear Power-The Next Fifty Years, Obninsk, 27 June-2 July 2004, CD-ROM, IAEA-CN-114-A3 Paper.

[2] U. Gat, "The Ultimate Safe (US) Reactor," Proceedings of ICENES-4, Madrid, 1987, pp. 584-595.

[3] V. M. Novikov, I. S. Slessarev, P. N. Alexeev, et al., "Nuclear Reactors of Enhanced Safety. The Analysis of Conceptual Designs," Energoatomizdat Publishers, Moscow, 1993, p. 52.

[4] International Atomic Energy Agency, "Advanced Nuclear Plant Design Options to Cope with External Events," 2006.

[5] A. V. Zrodnikov, G. I. Toshinsky, V. S. Stepanov, et al., "Nuclear Power Development in Market Conditions with Use of Multi-Purpose Modular Fast Reactors SVBR75/100," Nuclear Engineering and Design, Vol. 236, No. 14-16, 2006, pp. 1490-1502. doi:10.1016/j.nucengdes.2006.04.005

[6] "Safety Series, No. 75-INSAG-4," IAEA Publications, Vienna, 1990.

[7] B. F. Gromov and G. I. Toshinsky, "Technical and Economic Parameters of NPP and Safety," Atomnaya Energia (Nuclear Power), Vol. 78, No. 2, 1995, pp. 141-142.

[8] G. I. Toshinsky, I. M. Kurbatov and M. Ye. Amelina, "Economic Aspects of NPP Safety. Insurance against Risks," Teploenergetika, No. 11, 1998, pp. 47-50.

[9] O. M. Kovalevich, "Modern Tasks of Probabilistic Analysis of Safety of Sites Using Nuclear Energy," Atomnaya Energia (Nuclear Power), Vol. 104, No. 2, 2008, pp. 67-74.

[10] "Nuclear Power in Sweden," Nuclear Power Abroad, No. 9, 1991, pp. 16-21.

[11] I. S. Slessarev, "Nuclear Energy Strategy of a New Quality-Without Significant Hazards and Risks," Annals of Nuclear Energy, Vol. 35, No. 4, 2008, p. 636. htpp://www.proatom.ru/modules.php?name=News\&file $=$ article\&sid $=1863$ 